\section{THE LEGACY OF RUSSELL'S IDEALISM FOR HIS LATER PHILOSOPHY: THE PROBLEM OF SUBSTANCE}

\author{
Nicholas Griffin \\ Philosophy / McMaster University \\ Hamilton, Ont., Canada L 8 s $4 \mathrm{KI}$
}

$\mathrm{I}$

n my book Russell's Idealist Apprenticeship ${ }^{\mathrm{I}}$ I describe Russell's rejection of neo-Hegelianism very much from a logical point of view. The account I gave there is roughly this: Russell, as a found ond contradictions. In the end, he realized that all these problems had a common form and that they were contradictions only given a neo-Hegelian view of relations, which view he thus abandoned-thereby solving the problems and ceasing to be a neo-Hegelian.

Even before the book was published, this line of thought came in for criticism from Herbert Hochberg, in a review of a paper of mine on the same topic but written much earlier. ${ }^{2}$ The gravamen of Hochberg's complaint is that all this stuff about relations was pretty superficial and underneath it all was a Really Serious Metaphysical problem:

¿ Oxford: Clarendon P., I99I.

${ }^{2}$ N. Griffin, "The Tiergarten

well, eds. Antimonies and Paradorogramme" in Ian Winchester and Kenneth BlackOnt. An Aradies in Russell's Early Philosophy (Hamilton Ont.: McMaster U. Library P., 1989; also as Russell, n.s. 8 [1988]), Pp. I9-34.T paper was presented at a conference at the Univell, n.s. 8 [1988]), pp. 19-34. The review appears in Canadian Philosophical Unviversity of Toronto in 1984. Hochberg's

Unfortunately, Cacherial Reviews (1990): 168-72.

significance) in his lochberg does not return to the same issue (nor to much else of significance) in his surprisingly petulant review of the Apprenticeship book (Canadian Philosophical Reviews, I2 [Feb. 1992]: 28-30). There he generates a text by stringing differs in tone, sense and odd phrases to be found in the book. The text which results may suspect the may suspect the influence of Derrida in this reviewing technique.
G[riffin] overlooks two basic philosophical issues in R[ussell]'s work that are crucial to his own main theme-issues that occupied R[ussell] from the end of the Igth to the middle of the 2oth century: the analysis of particulars and the viability of appealing to relational differences to individuate particulars. (P. 170$)$

Now up to a point Hochberg's criticisms are quite correct. "Problems are paraded, but not probed" in my paper as Hochberg complains (ibid.). In my book I hope they are probed rather more, though Hochberg is no better pleased with the book than he was with the paper. For the approach in the book, though more detailed, is essentially the same, and the question of particulars and their diversity is not seriously addressed.

The truth is that I don't agree with Hochberg's estimate of the relative profundity of these two approaches-the logical which emphasizes relations and the metaphysical which emphasizes particulars (or, more generally, substances) - but I do not intend to argue against Hochberg's estimate here, for there seems to me abundant evidence that logic rather than metaphysics was at the top of Russell's agenda at this time. Metaphysical questions in general, and the problems of substances and their individuation, in particular, were not uppermost in his mind-except, perhaps, when he was thinking about Leibniz. ${ }^{3}$ This might well have changed had he ever got to the end of his neoHegelian encyclopedia of the sciences, at which point he would have to have confronted the metaphysical nature of the Absolute. But up to that point Russell, as a neo-Hegelian, was more concerned to answer the general question: Under what conditions are the special sciences possible?

On the other hand, Hochberg is right that the story can be given a metaphysical gloss, and in this paper I want to explain how. My book, as it were, treats Russell's neo-Hegelianism in what might be called the "logical mode", and in this paper I want to cover the same ground

${ }^{3}$ Cf. The Philosophy of Leibniz, Chap. Iv. The title of an unpublished article which Russell extracted from this book is instructive: "Leibniz's Doctrine of Substance as Deduced from his Logic" (RA 220.010820); the metaphysical doctrine was to be extracted from the logic and not vice versa. Russell's central claim in PL was that Leibniz had derived his metaphysics from a mistaken logical principle, the view that all propositions are of subject-predicate form. 
(much more briefly) in the "metaphysical mode". In choosing these terms, adapted from Carnap's famous distinction between the formal and material modes of speech, I want to suggest that, under appropriate (and reasonable) translations, the two modes will turn out to be equivalent, though the equivalence proof would likely require a good deal of (misplaced) ingenuity and is not to be attempted here.

If the equivalence hypothesis is correct the problems with relations that I have treated as central to Russell's abandonment of neo-Hegeliberg draws attention. claiming guise, occupied Russell thro in either its logical or its metaphysical when Russell's assell throughout his philosophical career. After 1914, when Russell's attention as a philosopher was primarily directed to treat the problem in the it becomes, I believe, much more natural to how the objects of the metaphysical mode, as a problem of showing structed out of common sense and the sciences could be conmore natural to treat primitive elements. Before 1914, however, it is the period from the period from 1898 to 1914 the task of translation would be especially ever, I shall -but not, I think, impossible. In the present paper, howi8ver, I shall concern myself only with the problem as it arose before sary first to recount the modes mesh for this early period it is necessary first to recount the problem in the logical mode in a little more

The contradictions that Russell, as a neo-Hegelian, uncovered in each of the special sciences were of a generic kind, which he called "the contradiction of relativity". Such contradictions occurred whenception" (Papers conception of difference without a difference of conception" (Papers 2: 166). Take, e.g., the concept of a point in geometry, where Russell first came across the contradiction. The contradiction arises there because all points are intrinsically exactly alike (they have no "difference of conception") and yet each is distinct on account of its relations to other points (so there is a "conception of

${ }^{4}$ I have sketched part of this account in "Terms, Relations, and Complexes" in Gary Wedeking and Andrew Irvine, eds., Russell and Analytic Philosophy (Toronto: U.

takes a similar line and extends the account beyond Igra. difference"). This is "the antinomy of the point".

The antinomy of the point is a genuine contradiction only because of Russell's neo-Hegelian theory of relations. For Russell, at this time, all relations were internal. By this he meant that they were "grounded" (to use the vague but then-fashionable phrase) on the intrinsic qualities $^{5}$ of their terms. In the case of asymmetrical relations, different intrinsic qualities were required for each term of the relation. And different relations require different intrinsic qualities in their terms. ${ }^{6}$ These three theses-(i) that relations are grounded on intrinsic qualities; (ii) that an asymmetrical relation is grounded on different qualities in each term; (iii) that different relations are grounded on different qualities-constitute Russell's doctrine of internal relations.

Once the doctrine is introduced it is immediately clear that the antinomy of the point is a genuine contradiction. Each point is intrinsically like every other. Yet each is different from all the others by virtue of its having different relations. But each different relation has to be grounded upon the different intrinsic qualities of its relata. ${ }^{7}$ Hence points cannot be intrinsically all alike.

As a neo-Hegelian, Russell hoped that the contradictions in a special science could be eliminated by a dialectical supercession to a wider science, so that relations between points could be cashed out in terms of relations between items which did differ intrinsically. By I898, however, he realized that this wasn't going to work, and he abandoned the doctrine of internal relations and with it the neo-

5 In what follows qualities are always represented by monadic predicates; relations by $n$-adic predicates $(n \geq 2)$. A quality, $F$, is intrinsic iff there is no quality $G$ and no item, $b \neq a$, such that $G(b)$ can be inferred from $F(a)$, without further premisses.

${ }^{6}$ Russell did not explicitly state this last thesis, and thus there is some slight doubt as to the correctness of attributing it to him. However, the thesis is essential if relations are to be eliminated in favour of intrinsic qualities, as many neo-Hegelians (including Russell) required. And, even if relations are not to be eliminated, it is natural to require that, if relations are to be grounded on intrinsic qualities, different relations should be grounded on different qualities. Otherwise the qualities which ground the relations would seem to serve no useful role in the theory. I suspect the thesis was not stated simply because Russell took it as obvious.

7 Typically in the case of geometry, and also in pure mathematics, terms had to be differentiated by means of asymmetrical ordering relations. In these cases, the antinomy is generated without appeal to the third thesis of Russell's theory of internal relations. 
Hegelian framework in which he had hitherto operated. Ever after, he regarded the doctrine of internal relations as the central feature of neo-Hegelianism. ${ }^{8}$ Having formulated the problem in the way I have, it takes little acumen to see that the doctrine of internal relations has to go. But this blatantly simplified account-designed for no other purpose than to make the solution look easy-does little justice to the remarkable insight and ingenuity that Russell exhibited in showing that a wide range of problems drawn from a variety of different sciences all had a common form and a common solution.

This, then, is the story told in the logical mode, and Hochberg objects to it in the following terms:

But R[ussell]'s "contradiction of relativity" is no mere offshoot of a doctrine of internal relations; it is concerned with the nature of particulars (individual "substances") and the ontological ground of their diversity.... [Griffin] fails to distinguish two quite distinct questions. One is whether a relation's holding between two things is grounded in monadic properties intrinsic to the things. The other is whether two things being diverse is grounded in their intrinsic properties. If diversity is a relation the two are easily confused. But $\mathrm{R}$ [ussell] holds ... that diversity is not a relation. One should then see the deep metaphysical issues involved. (Pp. 170-I)

Now, I think, to begin with, that the question of whether diversity is a relation is a red herring in this context. In the cases that Russell was primarily concerned with (points in geometry, quantities in arithmetic, centres of action in physics), the items in question could only be distinguished by means of asymmetrical ordering relations. That is, ordering relations were the only basis-relational or intrinsic-on which the diversity of different items of the same kind could be grounded. Ordering relations were genuine relations for Russell and moreover, relations which could not be eliminated. Whether diversity

${ }^{8}$ Cf., e.g., My Philosophical Development, Chap. 5; "The Monistic Theory of Truth" in Philosophical Essays, None the less, not all neo-Hegelians. (London: Allen \& Unwin, 1966), pp. 131-46. relations that Russell held. There is good reactly the doctrine of internal example, did not hold a doctrine of internad reason for thinking that Bradley, for Dispute between Russell and Master University, 199I). itself is a relation is irrelevant here, because the diversity of two items of these kinds has to be derived from their order, and order is indisputably a relation.

In the second place, it is quite wrong to say that I fail to distinguish the two questions. The first is the question of whether thesis (i) of Russell's doctrine of internal relations is correct. The second (in the form in which it is relevant) is the question of whether two things must be diverse in their intrinsic properties or whether they may be diverse on account solely of their relations to other things of the same kind. What links the two is Russell's discovery (arising from his analysis of the special sciences) that points, quantities and centres of action could only be diverse on account of their relations to other items of the same kind (or of another kind which exhibited the same type of relativity), and that these relations were ineliminable. Now if the diversity of items of a given kind depends upon their relations, then Hochberg's second question-is the diversity of these items grounded in their intrinsic qualities?-is answered along with his first-is a relation's holding between these items grounded in their intrinsic qualities? The diversity of the items can be grounded in their intrinsic qualities if, and only if, their relations can be so grounded. Hochberg's two questions are not so distinct as he seems to suppose, but what brings them together are the results Russell obtains from his analysis of the special sciences. With these results Hochberg's metaphysical mode and my own logical mode can be brought closer together.

From the metaphysical point of view the questions to be asked concern what exists rather than the consistency of the sciences. The special sciences were inconsistent because they required a plurality of items falling under their main categories and yet did not provide, within a neo-Hegelian framework, any consistent means of differentiating these items. For example, on Russell's account of geometry, the concept of a point is central and geometry required a multiplicity of points, yet it does not offer the conceptual resources necessary to distinguish different points. This showed, as Russell sometimes put it, that a world consisting entirely of points was impossible ( $c f$. Papers 2: 5).

Now put in this way, the problem is very similar to the problem of substance: Which items can be regarded as substances (where we mean by "substance" an item that is capable of independent existence)? 
What Russell, as a neo-Hegelian, hoped to show was that a dialectical supercession, in which one science was replaced by a wider one in which new conceptual resources were added, would eventually yield a single over-arching science, the subject matter of which, the Absolute, would be sufficiently all-encompassing to count as a substance. After some years' work on this enterprise, Russell came to realise that this was not a likely outcome unless the Absolute was construed in Bradleian terms as a single, relationless whole. This certainly guarantees the dent for there is the Absolute: Bradley's Absolute must be independependent But Rustich its existence could be that it ent. Bussell was unable to accept monism because he held might solve the prol scepticism.9 In other words, Bradleian monism impossible.

There are in fact two problems which might be called the problem
substance:

(I) What items are capable of existence independently of other items? (The problem of the existence of substance.)

and

(2) What is it for two items of a given kind to be distinct independently of other items? (The problem of the distinctness of sub-
stances). The second of these questions is closely linked to one of a more
epistemic cast, namely:

(3) Which kinds of items can be individuated independently of items of other kinds? (The problem of the individuation of substances.)

${ }^{9}$ His reasoning becomes apparent in An Essay on the Foundations of Geometry Difficulties of Continuous Quantity". "if also the remark deleted from "On Some every object of thought can only be : if [a thing] is simple, it is unthinkable, since 564, T53:24). The tem complexity" (Papers Russell's Idealist Apprenticeship, pp. I67-70, for com it expresses was not rejected. See
The second question concerns the identity conditions for items of a given kind; the third concerns their identity criteria.

It seems prima facie quite reasonable to link questions (I) and (2). For, we should not admit items of some category as capable of an independent existence, if the identity of items in that category depended logically upon other items. The existence of an item is its existence as the thing it is and not as another thing. This linkage is often expressed by the slogan: "No entity without identity". If this is the case-and Russell, at least, seems to have thought that it was ( $c f$. Papers 2: 278) - then no item is capable of independent existence which is incapable of independent identity. I shall assume henceforth that all substances are capable of both independent existence and independent identity. It is common, also-though in my view a common mistake-to link questions (2) and (3) through the slogan: "No identity without criteria". Russell may well have held such a view in his Kantian days ${ }^{\mathrm{IO}}$ - but could not have held it afterwards when he regarded the objects of knowledge as completely independent of our knowledge of them (MPD, p. I2). It is altogether too verificationist for my taste, and for Russell's also, in his Platonist days.

On the metaphysical interpretation of Russell's break with neoHegelianism, each instance of the contradiction of relativity can be taken as showing that the items in some scientific category cannot be regarded as substances.. It's important to realize, however, that, even if Russell had found some category of items which could stand as substances, he would still not have been able to free the system of the sciences from the contradiction of relativity without giving up the doctrine of internal relations. Suppose, e.g., that material atoms were genuine substances. ${ }^{\text {II }}$ We could then individuate geometrical points by means of their relations to the material atoms (e.g. a given point is that part of space which a given atom occupies at a determinate time or could occupy under determinate conditions). But on this account

to There is something of this view in Bradley, Principles of Logic, and ed. (Oxford: Clarendon P., I897; $1967 \mathrm{imp}$.), I: 65n.- a passage Russell cites with approval (Papers 2: $55 \mathrm{n}$.).

II This involves supposing that material atoms differ in their intrinsic qualities. In fact, Russell found material atoms to be infected with the same sort of relativity as geometrical points. 
all that has changed is that points are related to atoms instead of to other points. Different points still have different relations to atoms and, if the demands of the doctrine of internal relations are to be they must accordingly have different intrinsic qualities. So it's a mistake to think that a satisfactory theory of substance would have solved Russell's contradiction of relativity. The only way out of the contradiction of relativity is to abandon the doctrine of internal relations.

Conversely, abandoning the doctrine of internal relations does not in itself solve the problem of substance. Without the doctrine of internal relations points are no longer inconsistent, but they still cannot be treated as substances; for their identity depends upon the prior identity of items of another category. To solve the problem of substance requires the admission of items capable of existence and identity without reference to other items of the same or different category. And this, in turn, requires that items of that category can be distinguished by means of their intrinsic properties; that is, that their identity does not depend upon relations. Indeed, Russell, after he abandoned neoHegelianism, came to think that the problem of substance was entirely unsolvable and that this showed that the concept of substance was itself defective and ought to be abandoned. He puts the point concisely in The Philosophy of Leibniz:

Spinoza, we may say, had shown that the actual world could not be explained by means of one substance; Leibniz showed that it could not be explained by means of many substances. It became necessary, therefore, to base metaphysics on some notion other than that of substance-a task not yet accomplished. ( $P L$, p. 126$)$

Russell's first attempt to accomplish it was the new theory of terms that he came to in 1898 and presented in The Principles of Mathematics (1903). On it everything which can be thought of or referred to is a term (Papers 2: 167; PoM, p. 43). Terms are either simple or complex. Every simple term just is distinct from every other. It has what Russell calls "diversity of being"12 from every other simple term (Papers 2: I68). The problem of the ontological status of terms is solved by similarly draconian means. All terms simply are independently of all

${ }^{12}$ Or "material diversity" in the case of terms which exist. others. It is true that not all of them exist, but all of them have being (ibid.; PoM, pp. 43, 449).

The old problem of the individuation of points is then treated as follows:

Two parts of space or time themselves, however, have no intrinsic difference of predicate. If we wish to differentiate them, we must do so by their relations to the different things or attributes ${ }^{\mathrm{T} 3}$ which are in them. But since the latter derived their difference of predicates from the difference of position, our proceeding would become circular if we distinguished parts of space or time by relation to what occupied them. At some point of the circle, therefore, we must admit [diversity of being] without diversity of content. ${ }^{14}$ (Papers 2: 186)

A more general account is given rather more fully in the Principles, where Russell, pursuing a penchant for grammatical terminology, speaks of "subjects" and "predicates" rather than "terms" and "properties":

[I]t is a sheer logical error to suppose that ... subjects could be distinguished by differences of predicates. For before two subjects can differ as to predicates, they must already be two; and thus the immediate diversity is prior to that obtained from diversity of predicates. Again, two terms cannot be distinguished in the first instance by difference of relation to other terms; for the difference of relation presupposes two distinct terms, and cannot therefore be the ground of their distinctness. Thus if there is to be any diversity at all, there must be immediate diversity, and this kind belongs to points. (PoM, p. 452)

Since, on Russell's theory of terms, qualities are themselves terms, the difference of terms cannot always be traced back to difference of qualities. Complex terms may be distinguished by the fact that different simple terms compose them. But the simple terms themselves must be immediately different, whether they are subjects or predicates. The case which, on the old theory, would be treated as the inherence

${ }^{13}$ Spatio-temporally localized instances of qualities.

14 "Diversity of content" is the diversity which occurs when two terms have different qualities (Papers 2: 175). 
of a quality $q$ in a substance $s$, is to be treated on the new theory as the combination of two terms $q$ and $s$ into a complex term $q$-s. The scholastic distinction between substance and accident was thereby obliterated; items in both scholastic categories are terms.

If, at the level of simple terms, Russell had solved the problems of substance almost by fiat, he found himself still in difficulty over complex terms. And here, one can think of the old problem of substance coming back to haunt him in a new form. The identity conditions for complex terms were not a problem; as explained, they were parasitic upon the identity conditions of their constituent simple terms. What was a problem now was the unity of complex terms (or complex substances). At the end of his career, switching characteristically back to the logical mode, he put it this way:

I was concerned with what makes the unity of a complex, and, more especially, the unity of a sentence... I saw that the unity of a sentence depends upon the fact that it contains a verb, but it seemed to me that the verb means exactly the same thing as the corresponding verbal noun, although the verbal noun no longer possesses the capacity of binding together the parts of the complex. (MPD, p. 63)

Having treated the qualities and relations which occur in complexes as just further terms among their constituents, a complex seemed to be just an assemblage of terms. Yet complex terms must be more than just the set of their constituents. In some sense they must be unities, but it was difficult to see in what sense. ${ }^{.5}$

Is I explore these problems further in my paper "Terms, Relations, and Complexes" (see n. 4). Research for both papers has been supported by the Social Sciences and Hurnanities Research Council of Canada. 